\title{
PRÁTICA PEDAGÓGICA NA EDUCAÇÃO INFANTIL: O APRENDIZADO DAS PRIMEIRAS LETRAS
}

\section{PEDAGOGICAL PRACTICE IN EARLY CHILDHOOD EDUCATION: THE LEARNING OF THE FIRST LETTERS}

\author{
Guilherme Saramago de Oliveira ${ }^{1}$ \\ Márcia Regina Gonçalves Cardoso ${ }^{2}$
}

RESUMO: O presente texto relata algumas das análises e reflexões decorrentes de um estudo sobre o desenvolvimento da linguagem na Educação Infantil. Esse estudo teve como objetivos investigar os processos de como ocorre o ensino do prenome em turmas de crianças de dois anos de idade visando compreender os processos pedagógicos desenvolvidos pelas educadoras e os resultados decorrentes. O estudo buscou dar respostas a duas questões básicas. A primeira, como é feita a introdução ao ensino do prenome na educação infantil da rede municipal de ensino e a segunda, quais as ideações das crianças relacionadas a esses saberes. Para responder a estas questões e alcançar os objetivos propostos, foram estudados três grupos de colaboradores, sendo cada um deles constituído por uma professora e quinze alunos. Para coleta de dados foram utilizadas entrevista junto ao serviço de supervisão pedagógica da rede municipal e a observação direta do trabalho educativo realizado. Os fundamentos teóricos desta pesquisa se basearam nas mais influentes teorias sobre o desenvolvimento infantil: a psicanalítica, a de aprendizagem, a cognitiva, a contextual e a evolutiva sociológica. Os resultados do estudo indicaram que dentre outros aspectos, o lúdico, a alegria e a qualidade da interação professor-alunos parecem influenciar decisivamente o aprendizado infantil.

PALAVRAS-CHAVE: Educação Infantil; Prática Pedagógica; Desenvolvimento da Linguagem.

ABSTRACT: This paper reports some of the analyzes and reflections arising from a study of language development in early childhood education. This study aimed to investigate the processes occurring in the first name teaching classes of two years children in order to understand the pedagogical processes developed by educators and their results. The study attempted to answer two basic questions. First, how is the introduction to the teaching of first name in early childhood education in the municipal school and the second, what are the children's ideations related to this knowledge. To answer these questions and achieve the objectives were studied three groups of employees, each consisting of a teacher and fifteen students. For data collection were used interviews with the pedagogical supervision service and direct observation of the educational work. The theoretical foundations of this research were based on the most influential theories of child development: psychoanalytic, schooling, cognitive, contextual, and sociological. The overall result of this study indicated that, among other things, the playfulness, the joy and the teacher-students interaction quality seem to decisively influence the child learning.

\footnotetext{
${ }^{1}$ Doutor em Educação. Professor da Universidade Federal de Uberlândia/MG. E-mail: gsoliveira@ufu.br

${ }^{2}$ Mestrado Profissional em Tecnologias, comunicação e Educação pela Universidade Federal de

Uberlândia/MG. E-mail: mgcardoso2010@bol.com.br
} 
KEYWORDS: Early childhood education; Pedagogical practice; Language development.

\section{Introdução}

O presente texto relata algumas análises e reflexões decorrentes de uma pesquisa que buscou investigar os processos de como se dá a introdução ao ensino do prenome em turmas de dois anos da Educação Infantil, buscando compreender os processos de instrução desenvolvidos pelas educadoras/cuidadoras e os resultados de aprendizagem deles decorrentes.

Esta pesquisa buscou dar respostas a questões prioritárias. A primeira, como é feita a introdução ao ensino do prenome na educação infantil da rede municipal de ensino e a segunda, quais as ideações das crianças relacionadas a esses saberes. Para responder a estas questões e alcançar os objetivos propostos, foram estudados três grupos de colaboradores, sendo cada um constituído por uma professora e seus quinze alunos. Para coleta de dados foram utilizadas entrevista junto ao serviço de supervisão pedagógica da rede municipal e a observação direta.

Os fundamentos teóricos desta pesquisa se basearam nas cinco perspectivas teóricas principais que fundamentam as mais influentes teorias sobre o desenvolvimento infantil: a psicanalítica; de aprendizagem; a cognitiva; contextual e evolutiva sociológica.

\section{O desenvolvimento do pensamento e da linguagem}

A primeira ligação social de uma criança é com sua mãe ou a pessoa que desempenha esse papel. Conforme Oliva (2005), interações bebê-adulto determinam a qualidade de seu desenvolvimento e construções mentais. Logo, o vínculo parece ser uma fase necessária e fundamental no desenvolvimento inicial da criança e o primeiro passo no aprendizado social.

Essencial para essa primeira lição de confiança é a qualidade de comunicação. "Por meio da linguagem, as crianças formam conceitos sobre si próprias e sobre suas relações com os outros e aprendem a expressar necessidades pessoais e sociais" (FONTANA, 2002, p. 26).

Vygotsky (1991) considera a fala da criança tão importante quanto a ação para atingir um objetivo. Fala e ação faz parte de uma mesma função psicológica complexa, dirigida para a solução de um problema. A fala tem importância na operação como um todo. Observa que às vezes a fala adquire uma importância tão grande que, se não for 
permitido seu uso, as crianças pequenas não são capazes de resolver a situação, já que a fala parece ser o fio condutor que transporta o pensamento para ação.

Essas observações levaram o autor a concluir que as crianças resolvem suas tarefas práticas com a ajuda da fala, assim como dos olhos e das mãos. Segundo Vygotsky (1991), fala e ação, em última instância, provoca a internalização do campo visual e constitui o objeto central de qualquer análise da origem das formas humanas de comportamento.

Boa parte de seu desenvolvimento inicial, portanto, parece intensamente associado ao domínio que elas tiveram das habilidades linguísticas, bem como a qualidade da interação com os adultos e outras crianças.

O vínculo das crianças nos primeiros anos de vida não se limita a pai e mãe biológicos, mas ao principal adulto responsável por seus cuidados. São capazes de se ligar emocionalmente com outros adultos que lhe dão proteção e afeto. Pode ser uma avó ou pais adotivos, por exemplo.

É senso comum que criança proveniente de ambiente familiar seguro e com vínculos afetivos satisfatórios terá um bom relacionamento com seu professor e com seus pares.

Por outro lado, Fontana (2002) adverte que uma criança que demonstra no ambiente escolar atitudes de retraimento e hostilidade a adultos e a outras crianças em excesso e nenhum indício de ligação emocional, pode vir de um lar em que houve poucas oportunidades de aprender lições de vínculo. Essas atitudes seriam sinais do ciclo de privação afetiva.

Em relação à linguagem, Conforme Fontana (2002), acredita-se que as crianças têm capacidade inata de imitar sons. Inicialmente, os bebês imitam as expressões faciais dos adultos e os gestos que fazemos para eles. Nesse sentido, o autor cita Chomsky (1980) que alega que os bebês estão "geneticamente equipados" para adquirir a linguagem. Certamente não aprenderiam falar se não ouvissem pessoas falando ao seu redor, mas a estrutura já está presente desde o seu nascimento.

Consequentemente, considera ser importante o cuidador/professor aproveitar as oportunidades para conversar com a criança, usando linguagem apropriada, ouvindo com paciência e incentivando respostas. Atitudes de impaciência ou antecipação de palavras ou frases que a criança demora em concluir por certo só dificulta o desenvolvimento da criança. 
Em termos de desenvolvimento, Fontana (2002) menciona que Piaget (1951) sugere que $o$ ato de brincar ajuda as crianças a desenvolver formas mais complexas de pensamento. Uma criança que cresce em um ambiente com poucas oportunidades de brincar, manipular objetos, explorar cores, texturas, formas, onde a interação social é limitada aprenderá mais devagar do que aquela criada em um ambiente estimulante.

Vygotsky (1991), analisando como as crianças brincam e o significado da brincadeira, considera que o brinquedo cria uma zona de desenvolvimento proximal da criança já que no brinquedo, a criança sempre se comporta além do comportamento habitual de sua idade, como se ela fosse maior do que é na realidade. Brincar promove transformações internas no desenvolvimento da criança. Além disso, a mudança ocorre no desenvolvimento do próprio brinquedo, que vai de uma predominância de situações imaginárias para a predominância de regras.

\section{Teorias sobre o desenvolvimento infantil}

De acordo com Papalia, Olds, Feldman (2009) algumas influências no desenvolvimento originam-se principalmente da hereditariedade. Outras influências provêm, em grande parte, do ambiente, sendo considerado tanto as experiências vivenciadas no ambiente interno quanto externo. Qual desses fatores - hereditariedade ou experiências - tem mais impacto no desenvolvimento tem sido foco de intensos debates. "Os teóricos divergiram na importância relativa que deram à natureza (hereditariedade) e à criação (influências ambientais antes e depois do nascimento)" (PAPALIA; OLDS; FELDMAN; 2009, p. 12).

Hoje, pesquisas relacionadas as caraterísticas das crianças, quase todas apontam para uma mistura de herança e experiência. Assim apesar de a inteligência ser fortemente afetada pela hereditariedade, os fatores ambientais como família, comunidade, educação, cultura e influência do grupo também a afetam. "Embora ainda exista uma considerável disputa sobre a importância relativa da hereditariedade e do ambiente, os teóricos e pesquisadores contemporâneos estão mais interessados em encontrar caminhos para explicar como eles trabalham juntos". (PAPALIA; OLDS; FELDMAN; 2009 p. 12).

Segundo as autoras, outro fator importante a ser considerado no desenvolvimento da criança é a maturação. O desenvolvimento de capacidades como andar e falar, por exemplo, estão vinculadas ao processo de maturação do corpo e do cérebro. Esses 
processos maturativos atuam em conjunto com as influências da hereditariedade e do ambiente.

Nos processos de maturação pelos quais todas as crianças passam, o ritmo e a idade variam. Estão sujeitos às diferenças individuais. Assim, são consideradas idades médias. "Só quando o desvio em relação à idade aproximada é extremo devemos considerar o desenvolvimento excepcionalmente avançado ou atrasado" (PAPALIA; OLDS; FELDMAN; 2009 p. 13).

Analisando as múltiplas visões sobre fatores que intervém no desenvolvimento da criança, Madureira e Branco (p. 90) destacam que ora elas se concentram nas forças biológicas e maturacionais, ora destacam o papel do adulto como aquele que ensina às crianças. Em todas essas visões consideram que o papel reservado às crianças é de passividade.

Em contraposição, sustentam que tem surgido perspectivas teóricas que realçam o papel ativo das crianças no desenvolvimento dos aspectos psicológicos, por meio de interações no seu ambiente. Seria uma visão construtivista do desenvolvimento infantil, pois se concentra no caráter ativo da criança em seu contexto físico e sociocultural. Jean Piaget seria um representante dessa linha de pensadores.

Em que pese o crescente consenso sobre essas questões, muitos investigadores veem o desenvolvimento do ponto de vista de perspectivas teóricas diferentes. As teorias geralmente se enquadram nessas perspectivas amplas e cada uma delas enfatiza aspectos diferentes do desenvolvimento da criança.

Nesse sentido, conforme Papalia, Olds, Feldman (2009), apresenta-se cinco perspectivas teóricas principais que fundamentam as mais influentes teorias sobre 0 desenvolvimento infantil: a psicanalítica, que se concentra nas emoções e mecanismos inconscientes; de aprendizagem, sustenta que o desenvolvimento resulta da aprendizagem que se baseia na experiência ou na adaptação ao ambiente; a cognitiva, que analisa os processos do pensamento; contextual, que enfatiza o impacto do contexto histórico, social e cultural; e evolutiva sociológica, que considera as bases biológicas e evolutivas do comportamento.

Quanto a perspectiva psicanalítica, vê o desenvolvimento como moldado por forças inconscientes que motivam o comportamento humano. Entre os principais representantes dessa linha, as autoras citam Sigmund Freud (1953) e descrevem brevemente sua teoria. 
Freud acreditava que as pessoas nascem com mecanismos que devem ser redirecionados a fim de que seja possível viver em sociedade. A partir de observações realizadas em seus pacientes conclui que as origens dos distúrbios emocionais estão em experiências traumáticas reprimidas na infância.

Propôs que a personalidade é formada de três partes; o id, o ego e o superego. Os recém-nascidos são regidos essencialmente pelo id, o centro dos impulsos instintivos do inconsciente; consiste na busca da satisfação imediata do prazer. O superego, que se desenvolve por volta dos 5 ou 6 anos, contém a consciência moral, socialmente aprovados nos sistemas de valores. $O$ ego se refere ao eu consciente e se desenvolve de maneira gradual aproximadamente no primeiro ano de vida. Opera sob o princípio de mediação entre os conflitos do id e do superego.

$\mathrm{Na}$ teoria de Freud, a personalidade se forma mediante conflitos inconscientes entre as pulsões inatas do id e as exigências da vida civilizada. Esses conflitos ocorrem em uma sequência invariável de cinco estágios maturacionais do desenvolvimento psicossexual. Esses estágios seriam: o Oral (do nascimento aos 12-18 meses); Fase Anal (dos 12-18 meses aos 3 anos); Fálico (dos 3 aos 6 anos); de Latência (dos 6 à puberdade) e Genital (da puberdade `idade adulta).

Esclarecem Papalia, Olds, Feldman (2009), que a perspectiva da aprendizagem sustenta que o desenvolvimento resulta da aprendizagem, definida como uma mudança duradoura no comportamento que se baseia na experiência ou na adaptação ao ambiente. Os teóricos da aprendizagem veem o desenvolvimento de maneira contínua (não em estágios). Dentre as mais importantes teorias de aprendizagem citam 0 behaviorismo e a teoria da aprendizagem social (cognitiva social).

As autoras comentam que o behaviorismo é uma teoria mecanicista que descreve o comportamento observado como uma resposta previsível à experiência. Os behavioristas consideram o ambiente como principal impulso para o desenvolvimento infantil. Sustentam que os seres humanos em todas as idades aprendem da mesma forma que outros organismos. A pesquisa comportamental volta-se para a aprendizagem associativa classificada em condicionamento clássico e condicionamento operante.

Ambos os condicionamentos se relacionam a atividades de estímulo-respostareforço. A diferença entre os dois é que o condicionamento operante envolve um comportamento voluntário, ao contrário do outro. 
O condicionamento clássico pode ser aplicado a animais, como o fez Ivan Pavlov (1819-1936) em seus experimentos pioneiros com cães e em seres humanos, como fez John B. Watson (1878-1958). Ao aplicar as teorias de estímulo-resposta em experimentos com crianças pequenas, Watson afirmava que poderia moldar qualquer criança da maneira que quisesse. Para Watson, a aprendizagem se dava como o condicionamento clássico de Pavlov. Um estímulo neutro, depois de ser associado a um número suficiente de vezes como estímulo incondicionado, passa a eliciar a mesma resposta, podendo substitui-lo.

Outro behaviorista destacado no meio acadêmico, o psicólogo norte-americano B. F Skinner (1904-1990) formulou os princípios do condicionamento operante. "Descobriu que um organismo tende a repetir a resposta que tenha sido reforçada por consequências desejáveis e abolirá uma resposta que tenha sido punida". (PAPALIA; OLDS; FELDMAN; 2009 p. 31).

Skinner teve uma grande influência para educação. De acordo com sua concepção, o bom ensino depende de organizar eficientemente as condições estimuladoras. $\mathrm{O}$ ensino é um processo de condicionamento através do uso de reforço de respostas que se quer obter.

A teoria da aprendizagem social (cognitiva social) é outro modelo teórico dentro da perspectiva da aprendizagem. "A teoria da aprendizagem social clássica sustenta que a pessoas aprendem o comportamento social adequado pela observação e pela imitação de modelos - ou seja, observando outras pessoas" (PAPALIA; OLDS; FELDMAN; 2009, p. 32).

O psicólogo norte-americano Albert Bandura (nascido em 1925) desenvolveu muitos dos princípios da teoria da aprendizagem social. Sugere que o impulso para o desenvolvimento é bidirecional: "a criança atua no mundo enquanto o mundo atua na criança". (PAPALIA; OLDS; FELDMAN; 2009 p. 33)

Em relação a perspectiva cognitiva, as autoras afirmam que as teorias que se filiam a essa perspectiva enfatizam os processos de pensamento e o comportamento que reflete esses processos. Preocupa-se com o processo de compreensão, transformação, armazenamento e uso da informação. Procuram as regularidades nesse processo mental.

Dentre os teóricos cognitivistas, as autoras destacam a teoria dos estágios cognitivos de Piaget e a teoria sociocultural de Vygotsky. 
De acordo com Piaget, a criança tem uma capacidade inata para adaptar-se ao ambiente e que seu desenvolvimento passa sucessivamente por estágios, mais ou menos nas idades preestabelecidas, e que a velocidade do movimento por cada estágio, embora influenciada pelo ambiente e pela riqueza ou exiguidade das experiências oferecidas, é governada essencialmente por processos maturativos. Os estágios ou formas de pensamento descrito por Piaget (1951) são representados abaixo, conforme Fontana (2002).

O Estágio 1, denominado sensório-motor (aproximadamente do nascimento aos 2 anos) apresenta algumas características marcantes. Nas primeiras semanas de vida, a atividade infantil parece ter um caráter puramente reflexo, que se caracteriza por sugar, agarrar, chorar, estender braços e pernas quando se assustam. Em princípio essas atividades são direcionadas para o próprio corpo, mas em algum momento entre o quarto e o oitavo mês elas começam a ser cada vez mais dirigidas também a objetos externos.

Entre $012^{\circ}$ e $018^{\circ}$ mês, esses esquemas tornam-se cada vez mais elaborados à medida que a criança faz experiências com eles para obter os fins desejados. Um desenvolvimento importante durante este estágio é o crescimento de uma consciência da permanência de objetos, ou seja, as coisas continuam a existir mesmo depois que não estão mais presentes.

O Estágio 2, chamado de pensamento pré-operacional (aproximadamente 2-7 anos) é dividido por Piaget em dois subestágios: o subestágio pré-conceitual e o subestágio intuitivo.

No subestágio pré-conceitual (mais ou menos dos dois aos quatro anos), o desenvolvimento cognitivo é cada vez mais dominado pelo surgimento de atividade simbólica. As crianças tornam-se capazes de usar símbolos para representar ações. Vemos isso, por exemplo, na brincadeira infantil em que a criança torna-se a "mamãe" e a boneca torna-se o "bebê". Nessa fase com o desenvolvimento das habilidades de linguagem, as crianças passam a possuir o que Piaget chama de signos.

No subestágio intuitivo (mais ou menos dos quatro aos sete anos), as principais estruturas cognitivas utilizadas agora pela criança são denominadas por Piaget de egocentrismo, centração e irreversibilidade.

O egocentrismo se refere a uma fase em que as crianças não estão conscientes ainda de que há outros pontos de vista diferentes do seu, o que pode ser demonstrado 
quando se pergunta a ela, por exemplo, quais são os irmãos de um de seus irmãos (ela se deixará de fora, já que vê as coisas do seu ponto de vista).

A centração envolve a centralização da atenção num único aspecto de uma situação, desprezando outros. Uma experiência para investigar essa característica, é apresentar a criança duas bolas de massa que ela concorda serem do mesmo tamanho. Em seguida, uma das bolas é enrolada no formato de uma salsicha. Perguntada qual é a maior agora, costumam apontar para salsicha, pois se centram apenas num aspecto do problema, o comprimento, desprezando o peso ou a permanência da massa.

A irreversibilidade envolve a capacidade de retroceder a um ponto inicial. Assim, tendo percorrido certa sequência de três etapas, as crianças têm dificuldade para retornar à etapa dois e um.

No Estágio 3, o estágio das operações concretas (aproximadamente 7-11 anos), as crianças atingem um sistema simbólico de pensamento, porém ainda diferente daquele utilizado pela maioria dos adultos, vez que ainda está ligado a experiências concretas. Torna-se menos egocêntrica, desenvolvem a capacidade de descentralização (oposto do egocentrismo) e de reversão.

Com a descentralização vem a conservação. A principal estrutura cognitiva que se avança durante este estágio é o agrupamento (ou categorização). As crianças são capazes de reconhecer os membros de uma classe e organizar objetos e acontecimentos em conjuntos em torno de suas características comuns. Com a capacidade de agrupar vem também o que Piaget chamou de seriação: ou seja, a capacidade de dispor objetos em ordem segundo, por exemplo, tamanho ou peso.

No Estágio 4, denominado de operações formais (aproximadamente 12 anos em diante), embora o pensamento nesta fase possa ainda diferir em grau do pensamento adulto, eles se assemelham. As crianças já são capazes de formular uma hipótese sem necessitar da experiência efetiva dos objetos ou situações concretas.

$\mathrm{Na}$ teoria de Piaget há mais um aspecto importante que ele chama de invariantes funcionais. São aspectos inatos que uma vez alcançados permanecem constantes ao longo da vida. Os mais importantes deles são a adaptação que envolve duas fases: assimilação (refere-se à capacidade de receber novas informações e incorporá-las às estruturas existentes) e a acomodação (implica a capacidade de modificar as próprias estruturas cognitivas para incluir novas informações). A organização refere-se ao modo como ações cognitivas são agrupadas e arranjadas para formar sequências ou 
esquemas. Já a equilibração refere-se ao processo constante em buscar equilíbrio entre assimilação e acomodação.

Conforme Papalia, Olds, Feldman (2009), passemos a examinar a Teoria sociocultural ou sócio-interacionista de Vygotsky (1978), desenvolvida por um dos estudiosos mais sensíveis à influência da cultura e do ambiente sobre o desenvolvimento cognitivo, o psicólogo russo Lev Vygotsky. Para ele as capacidades cognitivas das crianças são construídas em interação com as oportunidades e orientação proporcionadas pelo ambiente, com destaque para o papel do adulto e os colegas mais avançados.

De acordo com Vygotsky (1978), essa orientação é mais eficaz para auxiliar a criança a cruzar a zona de desenvolvimento proximal (ZDP), o espaço entre o que ela já sabe e o que ela ainda não é capaz de fazer sozinha. Assim, a criança aprende por imitação, por interiorização dos processos cognitivos fornecidos por outros e pela prática. Portanto, o desenvolvimento cognitivo está muito mais relacionado aos aspectos culturais e sociais, e, por conseguinte, é fortemente dependente da linguagem e da interação social.

Em seus experimentos, Vygotsky (1978) identificou três estágios principais no desenvolvimento do pensamento infantil: estágio sincrético vago (em que as crianças dependiam basicamente de ações, numa base aleatória de tentativa e erro); estágio de complexos (em que a criança usava estratégias de complexidade variável, mas ainda não conseguia identificar os atributos desejados) e estágio de conceito potencial (quando a criança era capaz de lidar com os atributos correspondentes, mas não conseguia manipular todos ao mesmo tempo). Nesse nível de desenvolvimento, considerava-se que a capacidade de formar conceitos havia atingido a maturidade.

A perspectiva contextual sustenta que o desenvolvimento só pode ser compreendido em seu contexto social. Os contextualistas veem o indivíduo não como uma entidade separada interagindo com o ambiente, mas como parte inseparável dele.

A teoria bioecológica do psicólogo contextualista norte americano Urie Bronfenbrenner (1998), citado nos trabalhos de Papalia, Olds, Feldman (2009), descreve a variedade de processos interativos que afetam o desenvolvimento da criança. contexto pode promover ou inibir seu crescimento. Logo, o desenvolvimento ocorre por meio de processos de interação regular, ativa e bilateral entre uma criança em 
desenvolvimento e os processos ambientais diários e imediatos. Para entender esses processos, devemos estudar os vários contextos nos quais eles ocorrem.

Esses contextos começam com a casa, a sala de aula e a comunidade, conectamse externamente com instituições sociais, como os sistemas educacionais, e abrangem elementos culturais e históricos que afetam a família, a escola e a criança. O indivíduo não é simplesmente uma resposta do desenvolvimento, como um ser passivo, mas também atua como formador do seu desenvolvimento.

Analisam as autoras que a principal contribuição da perspectiva contextual foi a ênfase no componente social do desenvolvimento. $O$ foco das pesquisas passou da criança sozinha para localizá-la dentro de uma unidade maior (família, comunidade e instituições sociais). Ainda destacam como contribuição da perspectiva contextual o fato de que as descobertas sobre o desenvolvimento das pessoas em uma cultura ou de um grupo dentro de uma cultura, não podem ser aplicados igualmente a pessoas de outras sociedades ou grupos culturais.

Ainda de acordo com Papalia, Olds, Feldman (2009), a perspectiva evolutiva/sociobiológica proposta pelo biólogo americano E. O. Wilson (1975), é voltada para as bases biológicas e evolutivas do comportamento. Influenciados pela teoria da evolução de Darwin, os psicólogos do desenvolvimento evolucionário aplicam princípios evolucionários ao desenvolvimento da criança. Essa perspectiva recorre as descobertas da antropologia, da ecologia, da etologia, e da psicologia evolutiva para explicar o valor adaptativo, ou de sobrevivência, do comportamento para um indivíduo.

A abordagem evolutiva/sociobiológica não é necessariamente uma perspectiva teórica separada, posto que perpassa a teoria do desenvolvimento cognitivo, da aprendizagem social e do contextualismo.

Vários outros estudos sobre fatores que influenciam o desenvolvimento da criança utilizaram variáveis tais como o nível socioeconômico, fatores culturais, de gênero, raça, etnia e mesmo nutricionais. Em que medida esses aspectos determinam a qualidade e a velocidade que o pensamento e a linguagem vão se desenvolver e os reflexos disso na aprendizagem escolar já foram utilizados em outras pesquisas e fundamentaram outros constructos teóricos.

Apesar de não detalhadas nesse trabalho, certamente serão considerados na análise dos resultados encontrados. 


\section{Considerações sobre a teoria de Piaget e os behavioristas:}

Comenta Fontana (2002) que embora a teoria de Piaget tenha atraído críticas importantes, sua ênfase na criança como produto de uma interação entre maturação biológica e ambiente, em vez dos modelos exclusivamente maturativos ou ambientais do desenvolvimento infantil propostos por seus predecessores, é hoje universalmente aceita como adequada.

Nesse sentido, o professor deve ser sensível ao nível de pensamento que a criança está operando e examinar se o material de aprendizagem está adequado, de modo a oferecer-lhe atividades que promovam avanços em seu nível de pensamento.

De acordo com Hunt (1997), Piaget (1936), embora enfatizasse a "atividade como o alimento do esquema", concebeu que o olhar e o ouvir teriam importância-chave durante as primeiras fases do desenvolvimento intelectual, diferentemente dos behavioristas que acreditavam que o aspecto motor, mais do que o sensorial, seria o mais importante no processo da aprendizagem.

Nesse sentido, encontra-se nas citações de Hunt (1997), uma interessante pesquisa de Dennis e Dennis (1940), que verificaram que crianças índias da tribo Hopi criadas em pranchas que inibiam os movimentos das pernas e dos braços durante as horas de vigília andavam na mesma época que as crianças Hopi criadas em liberdade, embora passassem a maior parte do primeiro ano de vida com os movimentos limitados. Diferentemente, oitenta e cinco por cento das crianças num orfanato do Teerã ainda não andavam sozinhas por volta dos quatro anos de idade, apesar de poder usar livremente as funções motoras dos braços e das pernas.

As crianças Hopi criadas em pranchas não podiam exercitar seus membros livremente, mas estavam expostas, em virtude de ser carregadas às costas das mães, a uma rica variedade de estímulos auditivos e visuais, o que viria corroborar as ideias de Piaget (1936) já que para ele o olhar e o ouvir era extremamente valioso nos primeiros anos de vida da criança.

Esse caso evidencia também a importância dos fatores ambientais no desenvolvimento humano. A qualidade e a quantidade das experiências vivenciadas pelas crianças seriam fator preponderante no desenvolvimento dos aspectos físico, emocional, cognitivo e social, especialmente nos primeiros anos de vida.

\section{Caminhos metodológicos}


A pesquisa foi realizada junto a professoras e alunos da turma de dois anos de três centros educacionais infantis da rede municipal. Foram pesquisados três grupos distintos de colaboradores, sendo cada grupo composto por uma professora e seus quinze alunos. No total, 45 crianças fizeram parte desse estudo. A pesquisa ocorreu no final do ano de 2012.

Sabendo que nesta idade a rede municipal já introduz o trabalho com o prenome da criança, procuramos identificar como esses saberes são ensinados. Para tanto, realizou-se uma entrevista escrita junto à supervisora pedagógica responsável pela proposta pedagógica da educação infantil, com a seguinte indagação: como as professoras da turma de dois anos da educação infantil trabalham o primeiro nome com seus alunos? Além disso, foi realizada a observação direta do trabalho docente em sala de aula.

E para identificar as principais ideias apresentadas pelas crianças a respeito dos saberes inerentes ao estudo do prenome foi solicitada a resolução das seguintes atividades: fichas com o prenome de cada uma das crianças pesquisadas foram espalhadas pelo chão da sala e em seguida foi solicitado que cada uma identificasse o próprio nome.

Em outro momento foram espalhadas as letras do alfabeto e solicitado para que identificassem a primeira letra do nome. Observa-se que nas atividades propostas, as fichas com prenome e as letras do alfabeto tinham as mesmas características, ou seja, tamanho, cor de letra e forma eram semelhantes. Essa observação é importante para excluir a hipótese de que os acertos poderiam ser justificados por associação do nome com cor ou formato de letras diferentes.

\section{Resultados da pesquisa}

Pela análise dos dados obtidos na entrevista com a supervisora pedagógica, bem como pelas práticas observadas, ficou evidenciado que as professoras pesquisadas ensinam de forma diferente uma das outras. Chamaremos de grupo A, B e C.

O tempo dedicado ao trabalho com o prenome, a forma como acontece as atividades, a organização da sala, a rotina das crianças, os recursos materiais utilizados, se a professora trabalha com planejamento foram algumas das categorias observadas. 
A professora do grupo A senta-se com frequência no chão da sala, junto com seus alunos, fala calmamente, vibra com os avanços dos seus pupilos, incentiva-os a tentarem, mantém no grupo clima descontraído e calmo, o trabalho com o prenome e as letras do alfabeto é feito na forma de brincadeiras, sempre associando o nome que aparece na ficha a quem pertence, mostrando para todo o grupo. Além disso, é alegre, tranquila e canta com as crianças. A participação ativa das crianças é sempre incentivada pela educadora.

Do mesmo modo é o trabalho com a primeira letra do nome. Não há preocupação em trabalhar primeiro o alfabeto para depois mostrar a ficha com o prenome. As atividades são apresentadas concomitantemente, ao longo do ano, juntamente com os demais conteúdos curriculares. Dedica uma hora por semana para essas atividades. Apresentava-se bem receptiva a orientação prestada pela supervisora quanto ao planejamento e a metodologia indicada para trabalhar em sala.

A professora do grupo B tem um perfil diferente. Fala num tom um pouco mais alto, vibra muito com os avanços das crianças, canta, bate palmas, brinca. Suas aulas acontecem num clima de quase algazarra, com todos sentados no chão e fichas esparramadas. Que não pode ser confundido com desordem ou indisciplina. A palavra algazarra está sendo usada para passar a ideia de que as atividades observadas muito se assemelham a uma brincadeira descontraída. As atividades são dinâmicas, passando de uma para outra de meia em meia hora. Vibra muito com as respostas das crianças sobre o conteúdo. Trabalha com mais frequência o prenome, comparada com a professora do grupo A. Nos demais aspectos do processo de ensino, se assemelha a professora do grupo A.

A professora do grupo $\mathrm{C}$ apresenta uma metodologia diferente das duas outras. As crianças ficam o tempo todo sentadas na carteira, o clima das aulas é quase mecânico, as atividades com o prenome se resumem a ir ao quadro de pregas e apontá-lo. Ninguém levanta sem permissão, assim como não tocam no brinquedo colocado sobre a mesa enquanto a permissão não for dada. Quase não cantam e o perfil da professora é de falar menos. As brincadeiras, jogos e interações entre as crianças dessa turma não acontecem na frequência sugerida pela supervisora. A disciplina e o silêncio é algo muito valorizado pela professora. Não trabalha com frequência o prenome.

Diante do modelo de prática pedagógica desenvolvida pelas professoras, passemos a apresentar os resultados decorrentes das atividades proposta as crianças. 
No grupo A, de quinze, oito crianças conseguiram realizar com êxito as tarefas propostas. No grupo $B$, onze conseguiram. No grupo $C$ apenas três apresentaram as respostas desejadas.

\section{Analisando os resultados e concluindo}

De acordo com as teorias de desenvolvimento, fatores socioeconômicos não poderiam explicar a diferença de aprendizado, vez que os grupos pesquisados eram bem homogêneos, não apresentando diferenças culturais ou socioeconômicas significativas.

Os três grupos pesquisados são oriundos de centros educacionais municipais, localizados em bairros muito parecidos em termos de infraestrutura básica. Os prédios e materiais instrucionais são semelhantes. São orientados pela mesma supervisora pedagógica. Por fim, o projeto político pedagógico e o plano anual são iguais em toda rede municipal.

Tampouco aspectos relacionados à formação das professoras, pois a Professora Grupo A é Pedagoga; Professora do Grupo B (melhores resultados) só tem o curso técnico Normal (magistério); Professora Grupo C (pior desempenho) é magistério, também. Se a lógica da melhor formação fosse indicativa de melhor desempenho, então a professora A deveria obter os melhores resultados.

Quanto o tempo permanência na creche/escola, os grupos pesquisados ficam das 7:00 às 17:00, tempo bem significativo e igual para todos eles. O que poderia ser diferente é o ambiente e a qualidade das interações entre educadora/crianças e crianças/crianças.

Continuando a análise dos resultados, no Grupo A, oito crianças conseguiam realizar com êxito as atividades e sete não, e com significativa diferença de desempenho, ou seja, aqueles que conseguiam ainda identificavam dos colegas. Os demais demonstraram pouco interesse pelas atividades. A diferença, portanto, de desempenho entre os dois subgrupos (conseguiam e não conseguiam) era acentuada.

No Grupo B, além do melhor resultado (onze conseguiam e quatro não), aqueles que não conseguiam, demonstravam ter tido grandes avanços em outras atividades. Isso tornava o grupo bem homogêneo em termos de ideações desenvolvidas. Mesmo não conseguindo realizar com êxito as atividades propostas pela pesquisadora, o subgrupo que não conseguiu apresentou nível de desenvolvimento semelhante em outras atividades. As crianças que conseguiam, a exemplo daquelas do grupo $A$, também foram além do esperado, ou seja, identificavam o seu e dos colegas. 
No grupo C um fato chama atenção. Além do resultado ruim (três conseguiam e doze não), a professora demonstrava interesse maior pelos três de melhor êxito. Diante do grupo destacava os poucos que conseguiam realizar a tarefa proposta.

A única variável que foi possível isolar para tentar explicar a diferença de desempenho das crianças é o perfil das educadoras e a metodologia utilizada. É o que se mostrou diferente na análise dos resultados.

Portanto, tendo em vista os fundamentos teóricos educacionais que postulam a importância da relação harmoniosa, de confiança e respeito entre adulto/criança, criança/criança e do fazer com alegria, parece sensato atribuir os melhores resultados de desempenho das crianças, ao manejo de classe, a postura didático-pedagógica do educador, a forma como conduz o processo ensino-aprendizagem.

O lúdico, a qualidade da interação, da comunicação, assim como a dinâmica das atividades parece influenciar decisivamente o aprendizado infantil, especialmente na educação infantil.

\section{Referências Bibliográficas}

FONTANA, D. Psicologia para Professores. $2^{\underline{a}}$ edição São Paulo: Edições Loyola, 2002. $419 \mathrm{p}$.

MADUREIRA, A. F. A; BRANCO, A. M. C. U. A. Construindo com o outro: uma perspectiva sociocultural construtivista do desenvolvimento humano. In: DESSEN, M. A; JUNIOR, Á. L. C (orgs.). A ciência do desenvolvimento humano: tendências atuais e perspectivas futuras. Porto Alegre: Artmed, 2005. p. 90-109.

OLIVA, A. D. A noção de estado inicial e concepções de desenvolvimento: problemas e necessidade de definições empíricas dos termos. In: MOURA, M. L. S. De (Org.). O bebê Do Século XXI e uma Psicologia Em Desenvolvimento. São Paulo: Casa do Psicólogo, 2005. p. 61-110.

PAPALIA, D. E; OLDS, S. W; FELDMAN, R. D. O Mundo da Criança. 11ª edição São Paulo: McGraw Hill Brasil, 2009. 610 p.

HUNT, J. Mc V. O uso de programas pré-escolares de enriquecimento como um antídoto para a privação cultural: bases psicológicas. In: PATTO, M. H. S. (Org.). Introdução a Psicologia Escolar. 3ª edição São Paulo: Casa do Psicólogo, 1997. p. 97-144.

VYGOTSKY, L. A. A formação social da mente. 4. ed. São Paulo: Martins Fontes, 1991. 167 p. Tradução de José Cipolla Neto, Luis Silveira Barreto, Solange Castro Afeche. 
Revista InterteXto / ISSN: 1981-0601

v. 6, n. 1 (2013) 